\section{THE AMERICAN JOURNAL OF}

\section{PSYCHIATRY}

\section{Contents}

\section{December 2013, Volume 170}

\section{Editorials}

1379 Helping (some) SSDI beneficiaries with severe mental illness return to work

Richard G. Frank

1382 Looking schizophrenia in the eye

Dolores Malaspina

1385 Reassessing the safety of varenicline A. Eden Evins

13882013 in review

Robert Freedman, David A. Lewis, Robert Michels, Daniel S. Pine, Susan K. Schultz, Carol A. Tamminga, Arshya vahabzadeh

\section{Commentary}

1393 What's next for somatic symptom disorder? Joel E. Dimsdale and James Levenson

\section{Introspection}

1396 Where all and nothing is about mental health: beyond posttraumatic stress disorder for displaced Syrians Rami Bou Khalil

\section{Clinical case conference}

1398 Postanesthesia persistent amnesia in a patient with a prior history of dissociative fugue state: the case for the two-hit hypothesis Inna Roberts, Natalie Gluck, Michael S. Smith. and Mary F. Morrison

\section{Images in psychiatry}

1401 Partners at the 'interface' Don R. Lipsitt

\section{Reviews and overviews}

1403 SAD and the not-so-single photoreceptors

Dan A. Oren, Marek Koziorowski, and Paul H. Desan

\section{New research - articles}

1413 The Hotel Study: multimorbidity in a community sample living in marginal housing

Fidel Vila-Rodriguez, William J. Panenka, Donna J. Lang, Allen E. Thornton, Talia Vertinsky, Hubert Wong,

Alasdair M. Barr, Ric M. Procyshyn, J.J. Sidhu, Geoffrey N. Smith

T. Buchanan, Mel Krajden, Michael Krausz, Julio S. Montaner,

G. William MacEwan, and William G. Honer

1423 The cost of assisted outpatient treatment: can it save states money?

Jeffrey W. Swanson, Richard A. Van Dorn, Marvin S. Swartz, Pamela Clark Robbins, Henry J. Steadman, Thomas G. McGuire, and John Monahan

1433 Assisting social security disability insurance beneficiaries with schizophrenia, bipolar disorder, or major depression in returning to work Robert E. Drake, William Frey, Gary R. Bond, Howard H. Goldman, David Salkever, Alexander Miller, Troy A. Moore, Jarnee Riley, Mustafa Karakus, and Roline Milfort

1442 Emergency department recognition of mental disorders and short-term outcome of deliberate self-harm Mark Olfson, Steven C. Marcus, and Jeffrey A. Bridge

1451 Microvascular abnormality in schizophrenia as shown by retinal imaging

Madeline H. Meier, Idan Shalev, Terrie E. Moffitt, Shitij Kapur, Richard S.E. Keefe, Tien Y. Wong, Daniel W. Belsky, Honalee Harrington, Sean Hogan, Renate Houts, Avshalom Caspi, and Richie Poulton

1460 Varenicline, smoking cessation, and neuropsychiatric adverse events

Robert D. Gibbons and J. John Mann

1468 Drug-induced long QT in adult psychiatric inpatients: the 5-year cross-sectional ECG Screening Outcome in Psychiatry Study

François R. Girardin, Marianne Gex-Fabry, Patricia Berney، Dipen Shah, Jean-Michel Gaspoz, and Pierre Dayer

1477 Paralimbic cortical thickness in first-episode depression: evidence for trait-related differences in mood regulation Philip van Eijndhoven, Guido van Wingen, Maartje Katzenbauer, Wouter Groen, Ralf Tepest, Guillen Fernández, Jan Buitelaar, and Indira Tendolkar

1487 Neural correlates of emotional distractibility in bipolar disorder patients, unaffected relatives, and individuals with hypomanic personality

Philipp Kanske, Janine Heissler, Sandra Schönfelder, Johanna Forneck, and Michèle Wessa 